\title{
Assessing the causes of under-five mortality in the Albert Schweitzer Hospital service area of rural Haiti
}

\author{
Henry B. Perry, ${ }^{1}$ Allen G. Ross, ${ }^{2}$ and Facile Fernand ${ }^{3}$
}

Suggested citation

Perry HB, Ross AG, Fernand F. Assessing the causes of under-five mortality in the Albert Schweitzer Hospital service area of rural Haiti. Rev Panam Salud Publica. 2005;18(3):178-86.

ABSTRACT Objectives. Limited information is available regarding the causes of under-five mortality in nearly all of the countries in which mortality is the highest. The purpose of this study was to use a standard computerized protocol for defining the leading causes of death among children in a high-mortality rural population of Haiti and to highlight the need for similar studies elsewhere in Haiti and throughout the high-mortality areas of Latin America and the Caribbean. Methods. In 2001 a standardized, closed-ended verbal autopsy questionnaire endorsed by the World Health Organization was administered to a representative, population-based sample of the mothers or other caregivers of 97 children who had died before reaching 5 years of age between 1995 and 1999 in the service area of the Albert Schweitzer Hospital, which is located in the rural Artibonite Valley of Haiti. With the data from the questionnaires we used a computerized algorithm to generate diagnoses of the cause of death; the algorithm made it possible to have more than one cause of death.

Results. Acute lower respiratory infection (ALRI) was the leading diagnosis, present in $45 \%$ of all under-five deaths, followed by enteric diseases, present in $21 \%$ of deaths. Neonatal tetanus, preterm birth, and other early neonatal causes unassociated with ALRI or diarrhea were present in $41 \%$ of the neonatal deaths. Among children 1-59 months of age, ALRI was present in $51 \%$ of the deaths, and enteric diseases in $30 \%$. Deaths were concentrated during the first few months of life, with 35\% occurring during the first month. Among the neonatal deaths, $27 \%$ occurred on the first day of life, and $80 \%$ occurred during the first 10 days of life. Conclusions. In the Albert Schweitzer Hospital program area-and presumably in other areas of Haiti as well-priority needs to be given to the prevention of and the early, effective treatment of ALRI, diarrhea, and early neonatal conditions. This study points to the need for more, similar standardized assessments to guide local, regional, and national programs.

Key words Cause of death, data collection, autopsy, infant mortality, child mortality, child health services, Haiti.

Hôpital Albert Schweitzer, Deschapelles, Haiti (now with Future Generations, Franklin, West Virginia, United States of America). Send correspondence to: Henry Perry, Future Generations, HC 73 Box 100, Franklin, West Virginia 26807, United States of America; e-mail: henry@future.org; fax: 304-358-3008.

2 European College of Medicine, Rotherhithe, London, United Kingdom

3 Hôpital Albert Schweitzer, Deschapelles, Haiti.
There is a general recognition of the importance of accurate information regarding cause of death among children in the developing nations of the world. Nevertheless, accurate vital events registration systems for the entire population or even a small representative sample of the population are functioning in only a few of the developing countries that account for an overwhelming proportion of all the child deaths worldwide $(1,2)$. Just 42 nations with the largest numbers of deaths account for $90 \%$ of all the child deaths 
worldwide. However, among those 42 countries, only Mexico records the cause for more than $95 \%$ of the deaths (2). We are aware of only three published studies in English on the causes of death among children under 5 years of age in high-mortality countries in the Western Hemisphere $(1,3,4)$. Clearly, vital information on the causes of death in areas of high under-five mortality in the Americas is lacking.

Reducing under-five mortality continues to be a high priority throughout the developing world, given that 10.8 million children die annually from preventable causes (2). Reliable data to guide health policies and to improve prevention and treatment strategies are needed, particularly in those countries with the highest rates of under-five mortality $(2,5)$. Unfortunately, these countries have the weakest vital statistics and health information systems. Further complicating this picture is the fact that in studies that have used a verbal autopsy methodology to assess causes of child death, standardized approaches for measuring the causes of death have rarely been used (1).

Haiti has the highest under-five mortality in the Western Hemisphere, with approximately $12.5 \%$ of children dying before reaching the age of 5 years, followed by Bolivia, with 9.0\% (6). No other country in the Western Hemisphere has more than $5.0 \%$ of its infants dying before the age of 5 years (6). Hence, having accurate information on the cause of death for underfive children would appear to be a priority for the Government of Haiti and for private health organizations working in the country.

This paper reports the findings from a population-based verbal autopsy study using a standardized computerized diagnostic protocol carried out in the service area of the Hôpital Albert Schweitzer (Albert Schweitzer Hospital, or ASH), which is located in the rural Artibonite Valley of Haiti (Figure 1). ASH is the major source of primary health care and hospital services for the district known as the Unité Communale de Santé, Petite Rivière/ Verrettes/La Chapelle, which contains
FIGURE 1. Map of Haiti showing the location of Albert Schweitzer Hospital

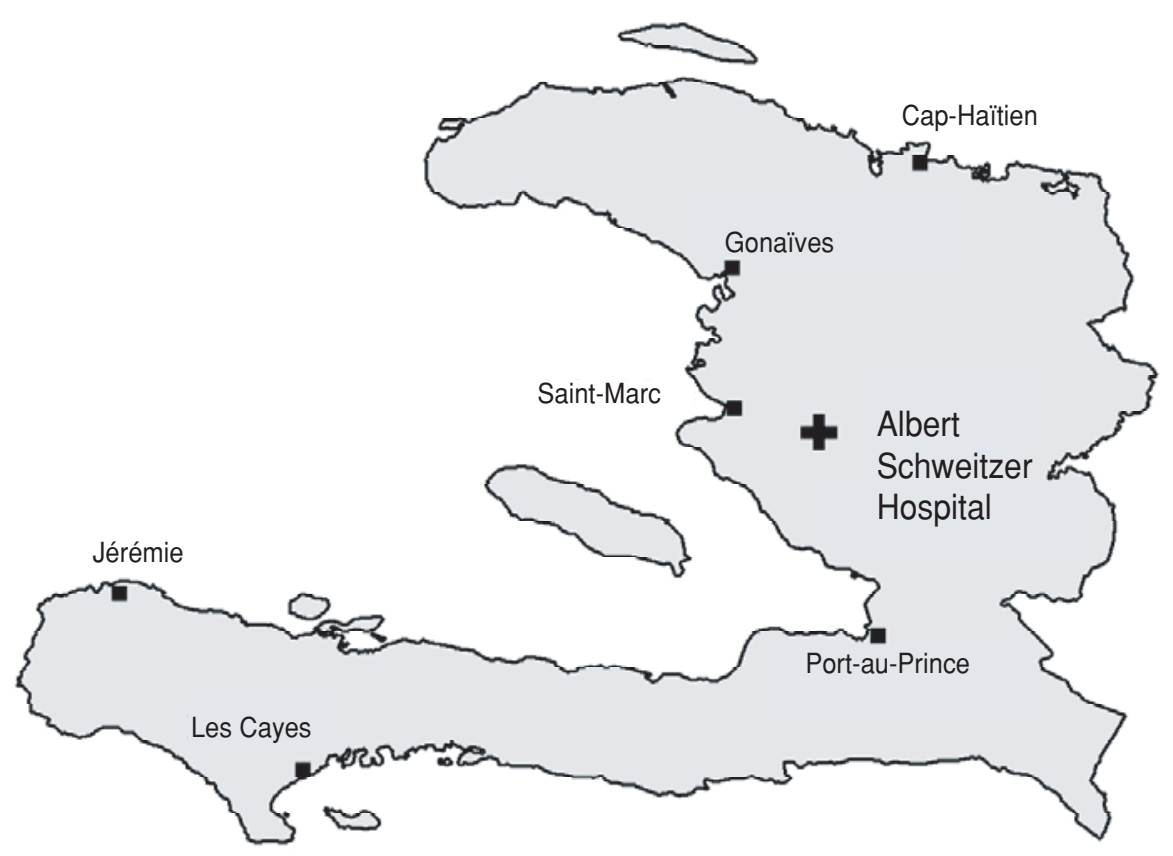

approximately 250000 people $(7,8)$. ASH is one of the few programs in the world that has documented an impact on under-five mortality in its service area (9), and its system of health and community development programs (including outreach services to the household level, plus hospital referral care) serves as a possible model for reaching the Millennium Development Goal of decreasing the underfive mortality rate worldwide by twothirds by the year $2015 .{ }^{4}$

\section{MATERIALS AND METHODS}

In the year 2000 a household survey of a random sample of 3247 women, representing $10 \%$ of the population of women of reproductive age in the ASH service area, identified 144 deaths among children less than 5 years old

\footnotetext{
4 Perry H, Northrup R, Bryant J, Berggren W, Berggren G. Reducing under-five mortality in severely impoverished settings through local health and development programs: policy implications from the experience of the Hôpital Albert Schweitzer. Article submitted for publication, 2004.
}

that had occurred between 1995 and 1999. In 2001 we carried out a follow-up survey with the households of the families of these 144 children in order to collect information on the cause of death, using a verbal autopsy questionnaire.

A trained team of five interviewers visited the mothers or other caregivers of the deceased children and administered the verbal autopsy questionnaire after receiving informed consent. The questionnaire consisted of 81 questions, in addition to ones to obtain identifying information. Not all the questions were necessarily asked. For instance, if there was no cough or difficulty breathing, the interviewer skipped 7 questions.

The questionnaire included more questions than were needed for the computerized algorithm that was used to assess the cause of death. The questionnaire included open-ended questions about the symptoms and cause of death that were intended to assist the respondent in recalling the circumstances prior to the death of the child. The responses to these open-ended questions, however, were not used to determine the diagnosis of the cause of 
death. The questionnaire took an average of about 30 minutes to complete. (A copy of the questionnaire in either English or Haitian Creole can be obtained from the senior author.)

The caregivers for 47 of the children who had died could not be located because they were temporarily away from home or had migrated. No caregivers refused to participate in the interview. The 97 children included in the study did not differ significantly in terms of age, sex, and geographical location from the 47 children for whom verbal autopsies could not be obtained. Among these 97 children, 34 died during the neonatal period, and 63 died between 1 and 59 months of age. Two-thirds $(66.0 \%)$ of the deaths occurred at home.

The computerized verbal autopsy protocol that was used to assess the cause of death in these children in Haiti had been tested in Bangladesh and endorsed by the World Health Organization (10-12). The protocol is "computerized" in the sense that once the data have been entered into the computer, the diagnosis is computer-generated.

Using simple programming instructions, the computerized protocol first determines if the death took place during the first 28 days of life. If so, the protocol then determines if a congenital abnormality was present or not. If so, this diagnosis is generated, and no further attempts are made to establish a diagnosis. If no congenital abnormality was present, then the presence of neonatal tetanus is assessed. If the symptoms of neonatal tetanus shown in Table 1 were not present, then the algorithm determines if an accident was the cause of death, and so on.

If the child died between 1 and 59 months of age, then the first step is to decide if an accident was the cause. Then it is determined if lower respiratory infection, dehydrating diarrhea, dysentery, persistent diarrhea, and/or measles were present, as defined according to the symptoms shown in Table 1 . These conditions are not mutually exclusive conditions, and they can be present simultaneously. Therefore, in the next step, the algorithm determines which of these are present
TABLE 1. Steps and criteria for assigning causes of childhood death, Albert Schweitzer Hospital service area, Haiti, 2001

\begin{tabular}{|c|c|}
\hline Diagnosis & Criteria \\
\hline \multicolumn{2}{|l|}{$\begin{array}{l}\text { Determination of cause of death } \\
\text { among neonates }\end{array}$} \\
\hline Step 1.a. & $\begin{array}{l}\text { All cases in which the death occurred during the first } 28 \text { days of } \\
\text { life are reviewed }\end{array}$ \\
\hline Congenital abnormality & Report of something physically wrong with the baby at birth \\
\hline Neonatal tetanus & $\begin{array}{l}\text { Death between } 4 \text { and } 14 \text { days of age, with convulsions reported } \\
\text { and (1) either normal crying at birth and stopped crying prior to } \\
\text { death or (2) normal suckling at birth with cessation of suckling } \\
\text { during the final illness reported }\end{array}$ \\
\hline Accident & $\begin{array}{l}\text { No "congenital abnormality" or "neonatal tetanus" but death } \\
\text { reported by accident (drowning, burn, poison, injury from fall, } \\
\text { traffic accident, bite, violence, or other) }\end{array}$ \\
\hline Preterm birth & $\begin{array}{l}\text { No "congenital abnormality," "neonatal tetanus," or "accident" but } \\
\text { birth occurring prior to the eighth month of pregnancy }\end{array}$ \\
\hline Delivery complication & $\begin{array}{l}\text { No "congenital abnormality," "neonatal tetanus," "accident," or } \\
\text { "preterm birth," but labor and delivery lasted longer than } 24 \text { hours }\end{array}$ \\
\hline Step 1.b. & $\begin{array}{l}\text { All cases among neonates previously diagnosed are excluded } \\
\text { from further diagnosis }\end{array}$ \\
\hline $\begin{array}{l}\text { Confirmed acute lower } \\
\text { respiratory infection (ALRI) } \\
\text { and/or confirmed neonatal } \\
\text { sepsis }\end{array}$ & $\begin{array}{l}\text { Presence of (1) both fever and rash or (2) either (a) report of } \\
\text { cough during the final two weeks of life that started at least } 3 \text { days } \\
\text { before death and that lasted until at least the day before death, } \\
\text { associated with at least two of six symptoms (noisy breathing, } \\
\text { stridor, grunting, wheezing, nasal flaring, or chest in-drawing) or } \\
\text { (b) report of difficult breathing during the final two weeks of life } \\
\text { that started at least } 1 \text { day before death and lasted until death, and } \\
\text { at least two of the same six symptoms noted above }\end{array}$ \\
\hline Confirmed diarrhea & $\begin{array}{l}\text { Report of frequent loose or liquid stools with a combined peak } \\
\text { number of day and night stools of six or more and at least two of } \\
\text { five specific symptoms (weakness, dry mouth, sunken eyes, } \\
\text { depressed fontanel, no or very little urine output) }\end{array}$ \\
\hline Step 1.c. & $\begin{array}{l}\text { All cases among neonatal deaths previously diagnosed are } \\
\text { excluded from further diagnosis }\end{array}$ \\
\hline $\begin{array}{l}\text { Possible ALRI and/or } \\
\text { neonatal sepsis }\end{array}$ & Report of skin rash or fever or cough or difficult breathing \\
\hline $\begin{array}{l}\text { Possible dehydrating } \\
\text { diarrhea }\end{array}$ & Report of frequent loose or liquid stools \\
\hline \multicolumn{2}{|l|}{$\begin{array}{l}\text { A combination of the } \\
\text { "possible" diagnoses in } \\
\text { Step 1.c. }\end{array}$} \\
\hline Step 1.d. & $\begin{array}{l}\text { All cases among neonatal deaths previously diagnosed are } \\
\text { excluded from further diagnosis }\end{array}$ \\
\hline Other early neonatal cause & Death during the first three days of life \\
\hline Not identified & No diagnosis made \\
\hline \multicolumn{2}{|l|}{$\begin{array}{l}\text { Determination of cause of death } \\
\text { among children } 1-59 \text { months old }\end{array}$} \\
\hline Step 2 & $\begin{array}{l}\text { All cases in which the death occurred between } 1 \text { month and } 59.9 \\
\text { months of age are reviewed }\end{array}$ \\
\hline Accident & $\begin{array}{l}\text { Death reported by accident (drowning, burn, poison, injury from } \\
\text { fall, traffic accident, bite, violence, or other) }\end{array}$ \\
\hline Confirmed ALRI & $\begin{array}{l}\text { Either (1) report of cough during the final two weeks of life that } \\
\text { started at least } 3 \text { days before death and that lasted until at least the } \\
\text { day before death, associated with at least two of six symptoms } \\
\text { (noisy breathing, stridor, grunting, wheezing, nasal flaring, or chest } \\
\text { in-drawing) or (2) report of difficult breathing during the final two } \\
\text { weeks of life that started at least } 1 \text { day before death and lasted until } \\
\text { death, and at least two of the same six symptoms noted above }\end{array}$ \\
\hline
\end{tabular}

(Continued on next page) 
TABLE 1. (Continued)

\begin{tabular}{ll}
\hline \multicolumn{1}{c}{ Diagnosis } & \multicolumn{1}{c}{ Criteria } \\
\hline $\begin{array}{l}\text { Step 2 (Continued) } \\
\text { Confirmed dehydrating } \\
\text { diarrhea }\end{array}$ & $\begin{array}{l}\text { Report of frequent loose or liquid stools during the two weeks } \\
\text { prior to death starting 1-13 days prior to death and continuing } \\
\text { until the day of death without blood in the stool and with a } \\
\text { combined peak number of day and night stools of six or more and } \\
\text { at least two of five specific symptoms (weakness, dry mouth, }\end{array}$ \\
& $\begin{array}{l}\text { sunken eyes, depressed fontanel, no or very little urine output) } \\
\text { Report of frequent loose or liquid stools during the two weeks } \\
\text { prior to death starting 1-13 days prior to death and continuing } \\
\text { until the day of death, with blood in the stool }\end{array}$ \\
$\begin{array}{l}\text { Confirmed dysentery } \\
\text { diarrhea }\end{array}$ & $\begin{array}{l}\text { Report of frequent loose or liquid stools beginning 14 days or } \\
\text { more prior to death and continuing until at least 3 days prior to }\end{array}$ \\
death & $\begin{array}{l}\text { Report of a new blotchy skin rash (small reddish eruptions) } \\
\text { mostly on the face and trunk without water inside the eruptions, }\end{array}$ \\
associated with fever and any one of three symptoms (dry cough, \\
red or running eyes, running nose), and age at death at least 6 \\
months
\end{tabular}

simultaneously. If no diagnosis is made by this point, then the algorithm attempts to determine if "possible ALRI" and/or "possible diarrhea" were present, as determined by the symptoms shown in Table 1. These can exist together. If no diagnosis is reached by this point, then an attempt is made to determine if possible malnutrition was present, as defined in Table 1. Finally, if no diagnosis is made at this point, the final diagnosis is "not identified."

Diagnoses for acute lower respiratory infection (ALRI) and diarrhea are classified as either "confirmed" (if a more stringent set of criteria are met) or "possible" (if less stringent criteria are met and another diagnosis is not made).
The protocol makes it possible to have more than one cause of death for any given child, such as "confirmed ALRI and possible dehydrating diarrhea" or "confirmed ALRI and confirmed persistent diarrhea."

Because the computerized algorithm is based on the answers to simple and direct closed-ended questions, there is less opportunity for subjectivity with this protocol than with protocols that rely primarily on open-ended questions.

Although malaria is present in the $\mathrm{ASH}$ service area, it is not common and rarely causes under-five mortality. Consequently, no provision was made to diagnose malaria using the verbal autopsy protocol.
Further information about the questionnaire and the method for computing diagnostic categories has been reported elsewhere $(10,11)$.

The data from the verbal autopsy questionnaires were analyzed using Epi Info version 6.04d software (Centers for Disease Control and Prevention, Atlanta, Georgia, United States of America).

\section{RESULTS}

The distribution of age at death shows that $55 \%$ of the under-five deaths occurred during the first 6 months of life, and that $35 \%$ occurred during the first month of life (Figure 2). Among the neonatal deaths, 27\% occurred on the first day of life, and $80 \%$ occurred during the first 10 days of life (Figure 3).

Table 2 and Figure 4 present the distribution of cause of death by age group. ALRI (both "confirmed" and "possible") was the leading single cause of death, accounting for $27 \%$ of the deaths. In another $11 \%$ of the deaths, the computerized algorithm made a diagnosis of either "confirmed ALRI and/or confirmed neonatal sepsis" or "possible ALRI and/or possible neonatal sepsis." And in another $7 \%$ of deaths, ALRI (either confirmed or possible) was present along with one of the enteric diseases (confirmed dehydrating diarrhea, confirmed persistent diarrhea, or confirmed dysentery). Thus, $45 \%$ of the under-five deaths were associated with ALRI (either confirmed or possible).

Enteric diseases were present in 13\% of the deaths. Confirmed dehydrating diarrhea, singly accounting for $7 \%$ of the deaths, was the dominant cause of death among the enteric disease group. Dehydrating diarrhea ("confirmed" and "possible") was present in combination with other diagnoses in an additional $5 \%$ of deaths. There was one diagnosis of "confirmed persistent diarrhea" singly and one case of "confirmed persistent diarrhea" in association with "confirmed ALRI." Dysentery was present as a single diagnosis or in combination with other diagnoses in $2 \%$ of 
FIGURE 2. Cumulative percentage of 97 childhood deaths, by age at death, among children with verbal autopsy, Albert Schweitzer Hospital service area, Haiti, 1995-1999

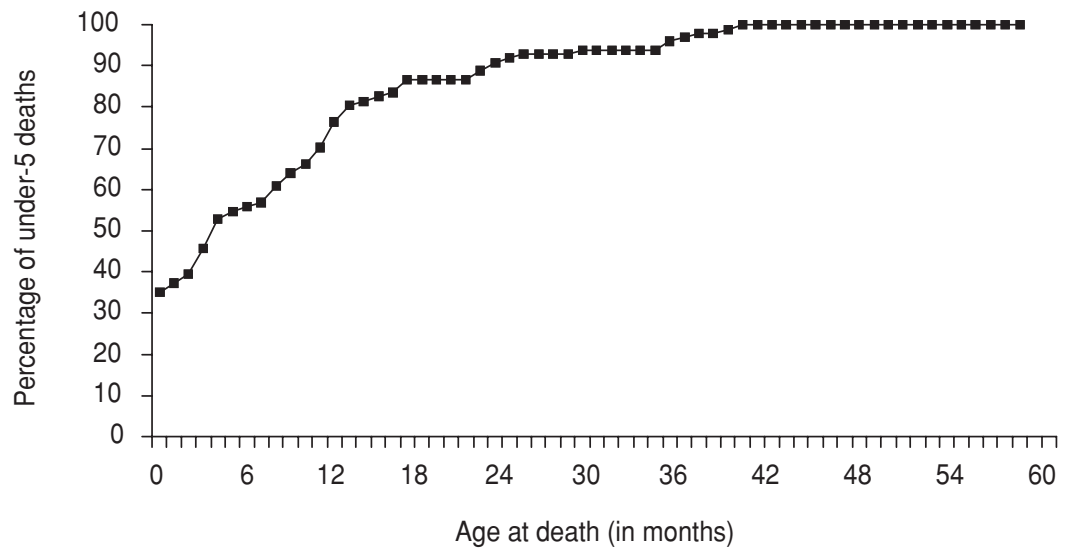

the deaths. Altogether, enteric diseases were associated with $21 \%$ of the deaths.

In the group dying in the neonatal period, ALRI/neonatal sepsis and perinatal conditions were the predominant causes of death. In the group dying in the neonatal period, ALRI and/or neonatal sepsis (confirmed and possible) and perinatal conditions ("preterm birth" or "other early neonatal causes") were the predominant causes of death. Neonatal tetanus accounted for $9 \%$ of newborn deaths.

Enteric diseases were almost nonexistent as a cause of death in this age group. In the group dying between 1 and 59 months of age, enteric diseases accounted for $21 \%$ of the diagnoses and, when combined with confirmed and possible ALRI, accounted for $30 \%$ of the diagnoses. Confirmed measles accounted for $2 \%$ of the deaths occurring from 1 to 59 months of age.

There was no significant difference in the distribution of deaths among those dying between 1 and 11 months of age and those dying between 12 and 59 months of age (data not shown). Among the 13 cases of children 1-59 months of age without a diagnosis, only 2 were reported to have been sick for 90 days or more; none had a cough, difficult breathing, or diarrhea prior to death; and none had evidence of wasting. Thus, it does not appear that there were any readily diagnosable cases of

FIGURE 3. Age at death (in days) among 34 infants dying during the neonatal period for whom a verbal autopsy was done, Albert Schweitzer Hospital service area, Haiti, 1995-1999

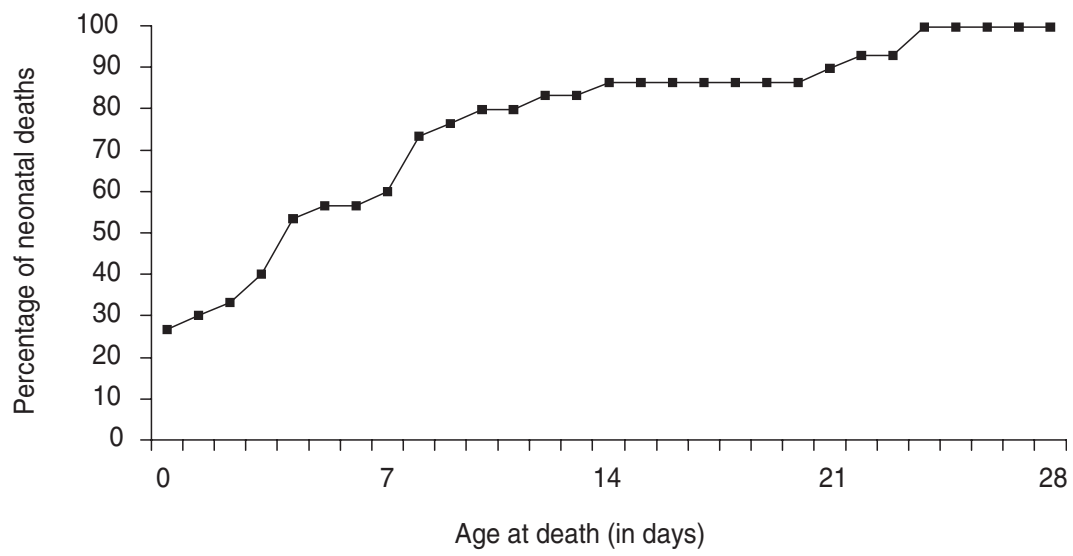

5 Perry H, Northrup R, Bryant J, Berggren W, Berggren G. Reducing under-five mortality in severely impoverished settings through local health and development programs: the long-term impact of the Hôpital Albert Schweitzer's programs in

Haiti. Article submitted for publication, 2005.

AIDS or tuberculosis among the residual undiagnosed cases.

\section{DISCUSSION}

In the Albert Schweitzer Hospital service area of rural Haiti, the leading causes of death among under-five children between 1995 and 1999 were ALRI, diarrhea, and early neonatal causes. Only $13 \%$ of the deaths occurred after 18 months of age.

Fortunately, the high rates of underfive mortality in Haiti nationally (13) as well as in the ASH service area ${ }^{5}$ have been gradually declining. The findings of our study indicate that further progress in reducing under-five mortality-at least in the ASH service area-will require continuing attention to strengthening preventive and curative approaches to these conditions. It is likely that the same priorities exist in other countries of the Western Hemisphere that have high levels of under-five mortality.

Data regarding cause of death among children in Haiti based on death certificates are incomplete, with only approximately $10 \%$ of deaths being registered (14), and with there being no evidence that these deaths are representative of all deaths. According to this incomplete information, the main causes of death are intestinal infectious diseases, infections of the perinatal period, malnutrition, and ALRI.

The 1994/1995 Demographic and Health Survey (DHS) obtained information on symptoms leading up to death (based on a verbal autopsy questionnaire) and on the mother's perception of the cause of death among children who died during the first 5 years of life (15). According to the DHS data, the leading causes of death during the neonatal period were low birthweight, complications of delivery, and neo- 
TABLE 2. Computer-generated diagnosis using verbal autopsy protocol for 97 children who died before reaching the age of 5 years between 1995 and 1999 in the Albert Schweitzer Hospital service area, Haiti

\begin{tabular}{|c|c|c|c|c|c|c|}
\hline \multirow[b]{2}{*}{ Diagnosis } & \multicolumn{2}{|c|}{$\begin{array}{c}0-28 \text { days } \\
(n=34)\end{array}$} & \multicolumn{2}{|c|}{$\begin{array}{l}1-59 \text { months } \\
(n=63)\end{array}$} & \multicolumn{2}{|c|}{$\begin{array}{c}\text { Total }(0-59 \\
\text { months) } \\
(n=97)\end{array}$} \\
\hline & No. & $\%$ & No. & $\%$ & No. & $\%$ \\
\hline \multicolumn{7}{|l|}{ Acute lower respiratory infection (ALRI) } \\
\hline Confirmed ALRI & 0 & 0.0 & 17 & 27.0 & 17 & 17.5 \\
\hline Possible ALRI & 0 & 0.0 & 9 & 14.3 & 9 & 9.3 \\
\hline \multicolumn{7}{|l|}{ Enteric diseases } \\
\hline Confirmed dehydrating diarrhea & 0 & 0.0 & 7 & 11.1 & 7 & 7.2 \\
\hline Possible dehydrating diarrhea & 0 & 0.0 & 4 & 6.3 & 4 & 4.1 \\
\hline Confirmed dysentery & 0 & 0.0 & 1 & 1.6 & 1 & 1.0 \\
\hline Confirmed persistent diarrhea & 0 & 0.0 & 1 & 1.6 & 1 & 1.0 \\
\hline Subtotal & 0 & 0.0 & 13 & 20.6 & 13 & 13.4 \\
\hline $\begin{array}{l}\text { Possible ALRI and/or possible neonatal sepsis and } \\
\text { possible dehydrating diarrhea }\end{array}$ & 1 & 2.9 & 0 & 0.0 & 1 & 1.0 \\
\hline Subtotal & 1 & 2.9 & 6 & 9.5 & 7 & 7.2 \\
\hline \multicolumn{7}{|l|}{ Other neonatal illnesses/conditions } \\
\hline Neonatal tetanus & 3 & 8.8 & 0 & 0.0 & 3 & 3.1 \\
\hline Preterm birth & 4 & 11.8 & 0 & 0.0 & 4 & 4.1 \\
\hline Other early neonatal causes & 7 & 20.6 & 0 & 0.0 & 7 & 7.2 \\
\hline Subtotal & 14 & 41.2 & 0 & 0.0 & 14 & 14.4 \\
\hline \multicolumn{7}{|l|}{ Other conditions } \\
\hline Injury/accident & 1 & 2.9 & 1 & 1.6 & 2 & 2.1 \\
\hline Congenital abnormality & 1 & 2.9 & 0 & 0.0 & 1 & 1.0 \\
\hline Confirmed measles & 0 & 0.0 & 1 & 1.6 & 1 & 1.0 \\
\hline Possible malnutrition & 0 & 0.0 & 3 & 4.8 & 3 & 3.1 \\
\hline
\end{tabular}

FIGURE 4. Major causes of death by age group, Albert Schweitzer Hospital service area, Haiti, 1995-1999

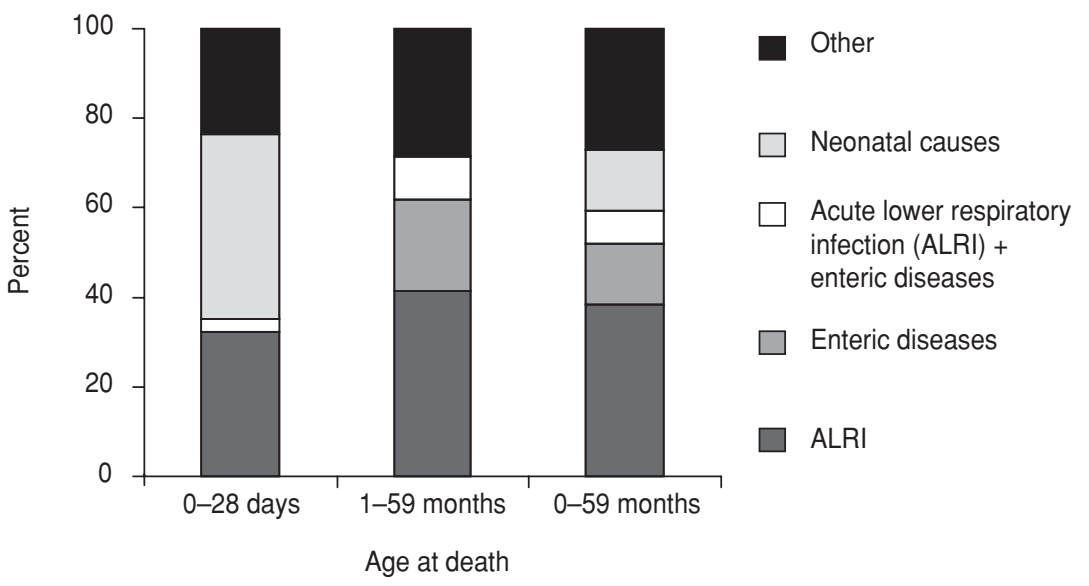

natal tetanus. For children 1-59 months old the leading causes were diarrhea, malnutrition, ALRI, and measles. Even though the DHS survey was based on a nationally representative sample of 359 deaths of under-five children, it used a nonstandardized questionnaire that required considerable subjective judgment in order to classify the causes of death.

In a study of infant deaths in the town of Mirebalais, Haiti, and the surrounding area, diarrhea was found to be the cause of $60 \%$ of the deaths among those 1-11 months of age, and ALRI, 11\% (16). The Mirebalais study included only deaths during the first year of life. In both the DHS and Mirebalais studies, diarrhea was a more 
important cause of death among those 1-11 months old than was ALRI.

However, in both studies, diarrhea and ALRI together accounted for approximately two-thirds of deaths in children 1-11 months old (and also in those 12-59 months old in the DHS study). In our study, ALRI (confirmed or possible) and/or enteric diseases (confirmed or possible) were present in $59 \%$ of the deaths.

Our study indicates that in the ASH service area ALRI is a much more important cause of death in under-five children than is diarrhea. Symptoms of diarrhea were present in $21 \%$ of underfive deaths, while symptoms of ALRI (and/or sepsis in newborns) were present in $45 \%$ of deaths. Since the two above-mentioned studies $(15,16)$ used different methods from ours to determine the cause of death, whether their findings represent truly different causes cannot be determined. One advantage of the methodology used in the ASH-area study was that it did not use open-ended questions to make the diagnoses. Another advantage was that the determination of cause of death was standardized, instead of being based on subjective assessments.

We have no data to support a claim that the method used in our ASH-area study is superior to other methodologies that have been used in Haiti or elsewhere. However, our method uses a straightforward method of collecting information on which the cause of death is based, and it also applies an objective and consistent manner of using this information to assess the cause of death. Therefore, measurement error becomes less with our method. Furthermore, with this method the findings from different sites, or from the same site at different points in time, should be more directly comparable.

Our study has some limitations. We cannot be completely certain that the cases included in our study are entirely representative of the ASH program area or of Haiti. Only two-thirds of the identified cases were available for follow-up, but the followed-up cases had demographic and geographic characteristics that were similar to those of the cases that were not available for follow-up. The ASH program area is not necessarily representative of rural Haiti because it has considerably higher levels of coverage of essential child survival services and lower under-five mortality. However, just because the mortality rates are lower does not necessarily mean that the proportion of deaths according to cause differs from other areas in Haiti (1). In addition, the sample size of 97 is small, particularly in view of the fact that there were 19 possible diagnoses, so verification of these findings with a larger sample size would be desirable.

Another limitation of this study is the verbal autopsy protocol itself. When deaths occur at home, family members' recall of events is less than optimal. However, in impoverished settings, the great majority of deaths occur at home without formal interaction with the health system (in our case, 66\%). Therefore, the verbal autopsy approach for ascertaining cause of death in impoverished settings is the best available. With verbal autopsy studies the sensitivity and specificity of diagnosing diarrhea are in the range of $36 \%$ to $96 \%$ and, for ALRI, $28 \%$ to $91 \%$ (1). Further work to validate specific verbal autopsy protocols is needed (17-20). However, using a standardized protocol with a computerized algorithm to generate diagnoses minimizes the subjective basis present in nonstandardized, open-ended questionnaires that do not use a computerized decision-making process to arrive at a diagnosis.

It appears that simplifying the process for collecting information about symptoms leading to death (by converting the questions used for diagnosis into ones that have a "yes" or "no" answer) and then using this information to establish a diagnosis using clear-cut, straightforward decision rules represents a step forward in the implementation of the verbal autopsy methodology. However, further research is needed to confirm this. Additional studies are needed as well on issues related to the validity of the information obtained when the death occurred several years earlier.

Using the same standardized protocol with computer-generated diag- noses based on clear-cut criteria helps to provide better comparability of findings from one setting to another. A protocol almost identical to the one that we used in our study was applied in Bangladesh, and it showed a similar distribution of causes, with a predominance of ALRI, diarrhea, and early neonatal causes $(10,11)$. Another advantage of the protocol that we used in Haiti is the capability to diagnose multiple causes for the same death.

ALRI, diarrhea, and early neonatal causes dominate the causes of death identified in published studies for Bolivia (4) and for Brazil (3). In a recent review of cause of death in under-five mortality in countries around the world, the leading causes found were ALRI, diarrhea, and early neonatal causes (1).

The verbal autopsy protocol employed in our Haiti study is unable to assess the contribution of AIDS, malnutrition, and tuberculosis to underfive mortality. In the ASH service area, $4 \%$ of women coming for prenatal care are HIV-seropositive. Approximately $20 \%$ of under-five deaths in the ASH service area are among HIV-positive children. Earlier research conducted in the city of Port-au-Prince, Haiti, demonstrated that causes of death among children born to HIV-positive mothers are indistinguishable from those born to HIV-negative mothers (21).

A high rate of childhood malnutrition also exists within the ASH service population. Based on weight-for-age criteria, $22 \%$ of the population has moderate or severe malnutrition. Based on heightfor-age criteria, $35 \%$ of the population is moderately or severely malnourished. Approximately 53\% of childhood deaths in Haiti have been attributed to malnutrition (22), and the level of malnutrition in the ASH service area is similar to that for the rest of Haiti. Of the under-five deaths occurring in the ASH service area, $31 \%$ occurred between the ages of 6 and 18 months, when the influence of malnutrition on under-five mortality is at its greatest. If rates of childhood malnutrition can be reduced within the ASH service area, then presumably the number of deaths in this age group will also decline. 
A high rate of tuberculosis also exists in Haiti, including in the ASH service area. Nationally, case detection rates are 136 per 100000 , and they are even higher in the ASH service area. Tuberculosis is known to be a cause of chronic malnutrition and death in children (23).

Thus, if child survival programs in Haiti are going to achieve the greatest possible impact, they must address, along with the other causes identified in our study, the underlying triad of childhood malnutrition, HIV infection, and tuberculosis. To further reduce underfive mortality, efforts will be needed to prevent childhood malnutrition (including zinc and vitamin A deficiencies), rehabilitate children with malnutrition, reduce mother-to-child transmission of HIV infection, and improve detection of cases of active tuberculosis.

Increasing the availability of community-based care by workers trained in the integrated management of childhood illness $(24,25)$, especially early antibiotic treatment of ALRI, has recently been recommended by the World Health Organization and the United Nations Children's Fund (26). Such efforts will

Morris S, Black R, Tomaskovic L. Predicting the distribution of under-five deaths by cause in countries without adequate vital registration systems. Int J Epidemiol. 2003;32:1041-51.

2. Black R, Morris S, Bryce J. Where and why are 10 million children dying every year? Lancet. 2003:361:2226-34.

3. Barros FC, Victora CG, Vaughan JP, Teixeira AM, Ashworth A. Infant mortality in southern Brazil: a population-based study of causes of death. Arch Dis Child. 1987;62:487-90.

4. Perry H, Shanklin DS, Schroeder DG. Impact of a community-based comprehensive primary healthcare programme on infant and child mortality in Bolivia. J Health Popul Nutr. 2003;21(4):383-95.

5. Lopez A. Commentary: estimating the causes of child deaths. Int J Epidemiol. 2003;32:1052-3.

6. World Health Organization. Child and Adolescent Health and Development [Internet site]. Available from htpp://www.who.int/childadolescent-health. Accessed 24 June 2004.

7. Nicholas S. Haiti's Hospital Albert Schweitzer: the legacy of Larimer and Gwen Mellon. Am J Public Health. 2003;93:527-9. have particular relevance in severely impoverished settings such as the ASH program area in Haiti. Finally, improved access to high-quality care for pregnancy complications $(27,28)$ as well as early antibiotic treatment of suspected neonatal sepsis should result in lower mortality during the early neonatal period (29).

Determining the leading causes of death as accurately as possible and also determining the age groups at greatest risk of death are fundamental steps in making a community diagnosis (that is, determining the most frequent, serious, readily treatable or preventable conditions within the community) and therefore in planning an effective program to improve child survival (30). The approach described here provides this key diagnostic information for one high-mortality area in Haiti. This same approach could be usefully applied in many other settings of high mortality in the Western Hemisphere.

\section{CONCLUSIONS}

The application of a verbal autopsy protocol in a representative sample of under-five deaths in a developing country with high mortality can assist in guiding program interventions and in assessing changes over time. In rural Haiti, ALRI, diarrhea, and neonatal causes predominate. Therefore, priority needs to be given to preventive and curative approaches that address these conditions and their underlying causes. The methodology used in this study has been used elsewhere, and it represents a feasible approach to making it easier to compare findings from different settings and to reducing the subjectivity involved in assessing causes of death.

Acknowledgements. We thank the caregivers who participated in this study and the interviewers who visited the homes of the caregivers. Robert Northrup provided valuable comments on an earlier draft, as did anonymous reviewers and the editorial staff of this journal. The Bill and Melinda Gates Foundation, the United States Agency for International Development, and the general operating funds of Hôpital Albert Schweitzer provided financial support for this study.

\section{REFERENCES}

8. Paris B. Song of Haiti. Perspect Health. 2000; 5(2):26-31.

9. Berggren WL, Ewbank DC, Berggren GG. Reduction of mortality in rural Haiti through a primary-health-care program. New Engl J Med. 1981;304:1324-30.

10. Baqui A, Black R, El Arifeen S, Hill K, Mitra S, al Sabir A. Causes of childhood deaths in Bangladesh: results of a nation-wide verbal autopsy study. Bull World Health Organ. 1998;76(2):161-71.

11. Baqui AH, al Sabir A, Begum N, El Arifeen S, Mitra SN, Black RE. Causes of childhood deaths in Bangladesh: an update. Acta Paed. 2001;90:682-90.

12. Anker M, Black RE, Coldham C. A standard verbal autopsy method for investigating causes of death in infants and children. Geneva: World Health Organization; 1999. (WHO/CDS/CSR/ISR/99.4).

13. Cayemittes M, Placide MF, Barrère B, Mariko S, Sévère B. 2001. Enquête Mortalité, Morbidité et Utilisation des Services (EMMUS-III) Haïti, 2000. Calverton: ORC Macro; Port-auPrince: Ministère de la Santé Publique et de la
Population and Institut Haitien de l'Enfance; 2001.

14. Pan American Health Organization. Core health data selected indicators. 2002. [Internet site]. Available from: http://www.paho.org/ English/DD/AIS/cp_332.htm/. Accessed 12 May 2005.

15. Cayemittes M, Rival A, Barrère B, Lereborus G, Gédéon MA. Enquête Mortalité, Morbidité et Utilisation des Services (EMMUS-II) Haïti, 1994/95. Calverton: ORC Macro; Port-auPrince: Ministère de la Santé Publique et de la Population and Institut Haitien de l'Enfance; 2001.

16. Désinor OY, Ferrus A, Deverson A, Bréa P, Desmangles B, Lerebours G, et al. Enquête sur la mortalité infantile à Mirebalais, Haïti. Sante. 2000;10:407-11.

17. World Health Organization. Measurement of overall and cause-specific mortality in infants and children: memorandum from a $\mathrm{WHO} /$ UNICEF meeting. Bull World Health Organ. 1994;72:707-13.

18. Anker M. The effect of misclassification error on reported cause-specific mortality fractions 
from verbal autopsy. Int J Epidemiol. 1997;26; 1090-6.

19. Mobley C, Boerma J, Titus S, Lohrke B, Shangula K, Black R. Validation of verbal autopsy method for causes of childhood mortality in Namibia. J Trop Ped. 1996;42:365-9.

20. Kahn K, Tollman S, Garenne M, Gear J. Validation and application of verbal autopsies in a rural area of South Africa. Trop Med Int Health. 2000;5(11):824-31.

21. Dowell SF, Davis HL, Holt EA, Ruff AJ, Kissinger PJ, Bijous J, et al. The utility of verbal autopsies for identifying HIV-1-related deaths in Haitian children. AIDS. 1993;7(9): 1255-9.

22. Pelletier D. The potentiating effects of malnutrition on child mortality: epidemiologic evidence and policy implications. Nut Rev. 1994; 52:409-15.

23. Hesseling A, Schaaf H, Gie R, Starke J, Beyers $\mathrm{N}$. A critical review of diagnostic approaches used in the diagnosis of childhood tuberculosis. Int J Tuberc Lung Dis. 2002;6(12):1038-45.
24. Bryce J, Victor C, Habicht J, Vaughan J, Black $R$. The multi-country evaluation of the integrated management of childhood illness strategy: lessons for the evaluation of public health interventions. Am J Public Health. 2004;94: 406-15.

25. Simoes E, Peterson S, Gamatie Y, Kisanga FS, Mikasa G, Nsungwa-Sabiiti J, et al. Management of severely ill children at first-level health facilities in sub-Saharan Africa when referral is difficult. Bull World Health Organ. 2003;81:522-31.

26. United Nations Children's Fund/World Health Organization. WHO/UNICEF joint statement: management of pneumonia in community settings. New York: UNICEF; 2004. (UNICEF/PD/Pneumonia/01).

27. McCord C, Premkumar R, Arole S, Arole R. Efficient and effective emergency obstetric care in a rural Indian community where most deliveries are at home. Int J Gynaecol Obstet. 2001;75(3):297-307.
28. Bang R, Bang A, Reddy M, Deshmukh M, Baitule S, Filippi V. Maternal morbidity during labour and the puerperium in rural homes and the need for medical attention: a prospective observational study in Gadchiroli, India. BJOG. 2004;111:231-8.

29. Bang AT, Bang RA, Baitule SB, Reddy $\mathrm{MH}_{\text {, }}$ Deshmuck MD. Effect of home-based neonatal care and management of sepsis on neonatal mortality: field trial in rural India. Lancet. 1999;354(9194):1955-61.

30. Perry H, Robison N, Chavez D, Taja O, Hilari C, Shanklin D, et al. Attaining health for all through community partnerships: principles of the census-based, impact-oriented approach developed in Bolivia, South America. Soc Sci Med. 1999;48:1053-67.

Manuscript received 21 December 2004. Revised version accepted for publication 13 May 2005.
RESUMEN

\section{La evaluación de las causas de mortalidad en niños menores de cinco años en la zona rural atendida por el Hospital Albert Schweitzer de Haití}

Objetivos. Hay poca información acerca de las causas de mortalidad en niños menores de cinco años en casi todos los países donde la mortalidad alcanza las cifras más altas. El objetivo del presente estudio fue usar un protocolo computadorizado estandarizado para determinar cuáles son las principales causas de muerte entre los niños de una zona rural de Haití que tiene tasas de mortalidad elevadas, así como llamar la atención a la necesidad de realizar estudios semejantes en otros lugares de Haití y en todas las zonas de América Latina y el Caribe donde la mortalidad es alta.

Métodos. En 2001 se administró un cuestionario estándar de autopsia verbal a base de preguntas cerradas, respaldado por la Organización Mundial de la Salud, a una muestra poblacional representativa de las madres o guardianes de 97 niños que habían fallecido entre 1995 y 1999 antes de cumplir los 5 años de edad en la zona atendida por el Hospital Albert Schweitzer, situado en el valle rural de Artibonita en Haití. Los datos obtenidos mediante los cuestionarios permitieron crear un algoritmo computadorizado para generar los diagnósticos asociados con la causa de muerte. El algoritmo daba cabida a más de una causa de muerte.

Resultados. La infección respiratoria baja (IRB) fue el diagnóstico más frecuente, habiéndose encontrado en $45 \%$ de las defunciones de niños menores de 5 años. Le siguieron las enfermedades entéricas, que se hallaron en $21 \%$ de los casos. El tétanos neonatal, el nacimiento prematuro y otras causas neonatales tempranas que no se asociaban con una IRB ni con diarrea estuvieron presentes en $41 \%$ de los casos de muerte neonatal. Entre los niños de 1 a 59 meses de edad, se encontró el diagnóstico de IRB en $51 \%$ de los casos de defunción y el de alguna enfermedad entérica en 30\%. Las defunciones se produjeron eminentemente en los primeros meses de vida, con $35 \%$ de ellas durante el primer mes. De las muertes neonatales, $27 \%$ tuvieron lugar durante el primer día de vida, y $80 \%$ en los primeros 10 días después de nacer.

Conclusiones. En la zona abarcada por el programa del Hospital Albert Schweitzer, y probablemente también en otras zonas de Haití, hay que darles prioridad a la prevención y al tratamiento temprano y eficaz de las IRB, la diarrea y los trastornos propios del período neonatal temprano. Este estudio apunta a la necesidad de llevar a cabo más evaluaciones estandarizadas de igual naturaleza para orientar las actividades de los programas locales, regionales y nacionales. 